Stephan VOELKER ${ }^{1}$, Sabine Raphael ${ }^{2}$, Peter Raynham ${ }^{3}$

University of Technology Berlin (1), Max Planck Institut Köln (2), London's Global University (UCL) (3)

\title{
White light in Road and Car lighting
}

Abstract. The article deals with the use of white light for car and road lighting. It starts with a basic investigation about brightness evaluation of different headlamps (H7, D2S, LED). The relevance of peripheral viewing for night time trafic is discussed in a second part. The last part of this article presents that differences in the light distribution are more important than differences in the lamp spectrum.

Keywords: White light, mesopic, car lighting, road lighting

\section{Introduction}

The cost of energy is increasing year by year, this, coupled with the fact that we need to reduce $\mathrm{CO}_{2}$ emissions, has led a lot of municipalities to try to reduce the amount of energy they use. Therefore, there is interest in ways of reducing the amount of energy consumed by street lighting while at the same time maintaining the beneficial impacts of the lighting. The current British Standard for Street Lighting [1] permits the reduction of light levels on residential roads if a light source with a colour rendering index greater than 60 is used.

There have been a number of studies for instance [2, 3, 4], about mesopic vision that have shown the advantages of light sources with more short wave radiation. This gives rise to the question should we replace all sodium lamps with white light sources? Clearly there is the question of the cost of the changeover, but have we reached the stage where no new installations based on sodium lamps should be installed? Also why is the reduction in lighting level only used on residential roads?

\section{Purpose of street lighting}

Before any discussion of the impact of various light sources, it is necessary to examine the purpose of street lighting. Drivers are interested in safe movement, visual orientation and visual comfort. The interests of pedestrian are safe movement (detection of obstacles), visual orientation and facial recognition followed by a general feeling of comfort and safety. Drivers and pedestrians tend to look at different areas, they are interested in completely different areas of view and this means that they have different lighting requirements. Pedestrians need to see objects at relatively short distances whilst drivers need to see things that are further away. An analysis of the lighting requirements of pedestrians and drivers is given below. A review of publications of the last few years reveals:

- White light is more pleasant for pedestrians [5, 6],

- Colour recognition is better under white light compared to yellow light $[6,7,8]$,

- Peripheral pedestrians are more visible under white light $[9 a, 9 b]$

- Recognition of faces by pedestrians is better [6, $9 b]$.

White light improves the quality of the lit environment significantly for pedestrians.

This gives rise to the question of what is known about the impact of white light on drivers. There has been some research that has shown off-axis object detection is better under white light $[2,3,10,11]$. However, it is not clear what the consequences of these findings are for the design of headlights and street lighting. The object of this paper is to report the findings of some experiments that have been carried out to give more information on this subject.

\section{Influence of the spectral distribution on the brightness}

It has long been known that at low light levels (in the mesopic region) the eye becomes more sensitive to short wavelength radiation as the luminance level decreases. The spectrum of the recently introduce LED headlamps is completely different to the light sources used in conventional headlamps. Figure 1 gives the spectral power distribution of LED headlamps together with the spectra of conventional headlamps.

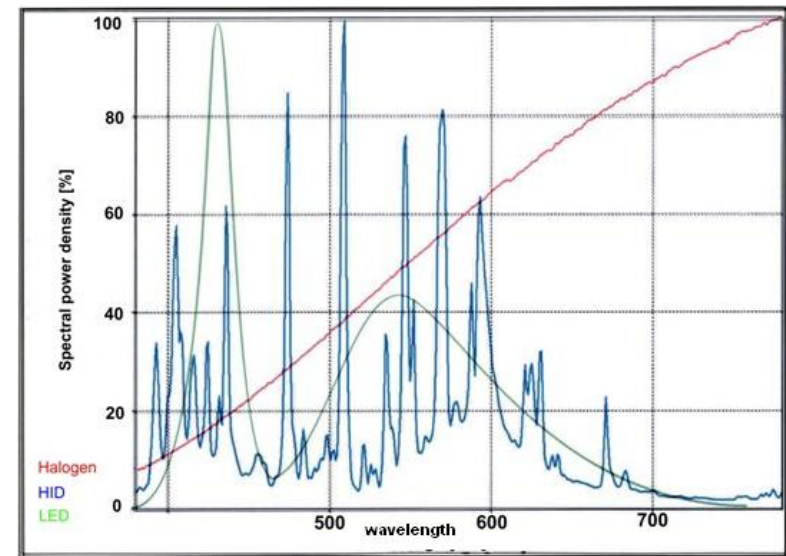

Figure 1. Spectral distribution of different light sources for headlamps

Initial tests have indicated that LED headlights may be brighter than halogen headlights with equal photometric performance. Gottschalk [12] investigated the variation in brightness between halogen, gas discharge (HID) and LED headlamps. A summary of the work is presented below.

A brightness matching method was used for this investigation. Figure 2 is a diagram showing the general layout of the test facilities. There were 27 test subjects who took part in this experiment (age: 20 - 45, without any visual defects).

The test subjects sat in front of two test screens (figure 3). The screens each subtended an angle of $20^{\circ}$ at the test subject's eye. The reference light was presented on the left side (H7 and D2R) and the test light source on the right (H7, D2R, LED). The photometric data of the light sources used is given in table 1 . A total of 6 tests were carried out with different combinations of light sources and luminance values of 1 and $5 \mathrm{~cd} / \mathrm{m}^{2}$.

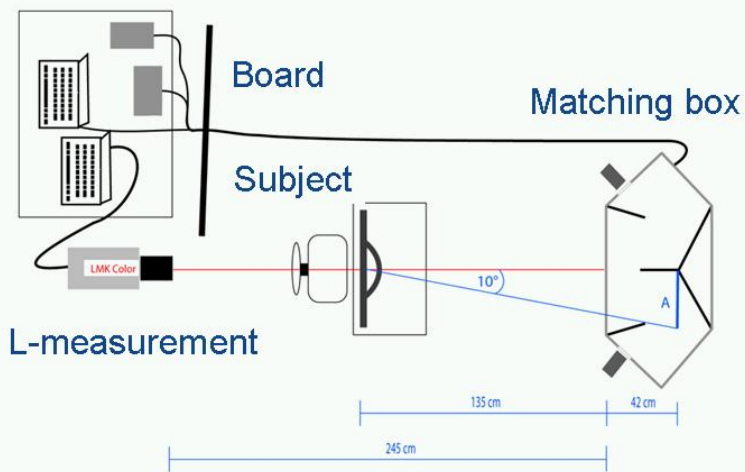

Figure 2. Testing facilities for the brightness matching [12] 


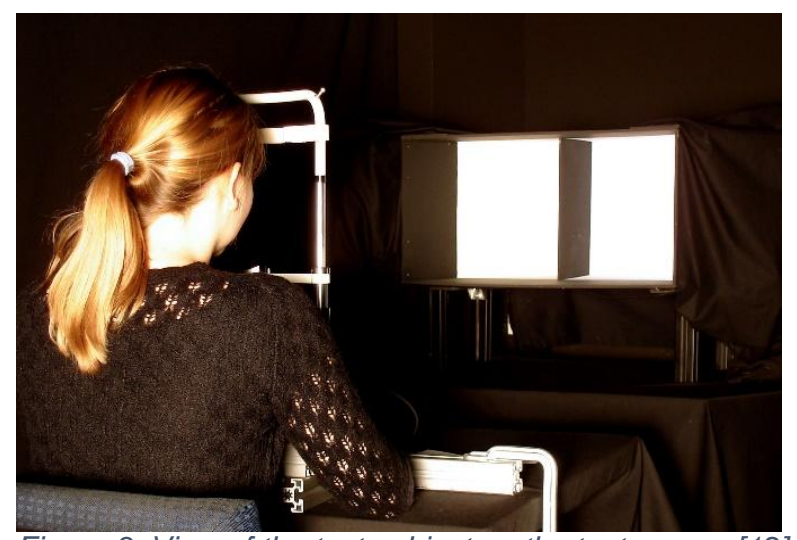

Figure 3. View of the test subject on the test screen [12]

Table 1. Photometric data of the used light sources

\begin{tabular}{|l|l|l|l|}
\hline $\begin{array}{l}\text { Light } \\
\text { source }\end{array}$ & S-P ratio & TC & Ra \\
\hline H7 & 1,4 & $2900 \mathrm{~K}$ & 100 \\
\hline D2R & 1,6 & $3300 \mathrm{~K}$ & 72 \\
\hline LED & 2,2 & $5500 \mathrm{~K}$ & $\mathrm{n} / \mathrm{a}$ \\
\hline
\end{tabular}

The tasks of the test subjects were to adjust the luminance of the test screen (right hand screen) so that it matched the reference screen in terms of brightness. The subject had to match the brightness of each reference screen four times, twice when the brightness of the test screen was lower than that of the reference screen and twice when it was higher. This method is known as up-and-down-method [12].

In an article of Fotios and Cheal [8] is pointed out a bias, what is based on the testing facilities using in the presented study. The described effect seems however much smaller than the influence of the high blue content of the spectral distribution of LED.

Figure 4 shows the results of the test. The pairs of bars show the luminances of the two screens at the point of matched brightness. The left-hand bar of each pair gives the luminance of the reference screen and the right-hand the test screen.

Gas discharge headlamps and LED headlamps were judged to be brighter than halogen headlamps at equa photopic luminance. This effect increases with higher luminances and greater visual angle. The influence of the visual angle was tested in an additional pilot study (5 test subjects; $36^{\circ}$ visual angle).

Table 2 shows the relative decrease in luminance of the test source as compared to the reference source. The values in the table are evaluated using formula (1):

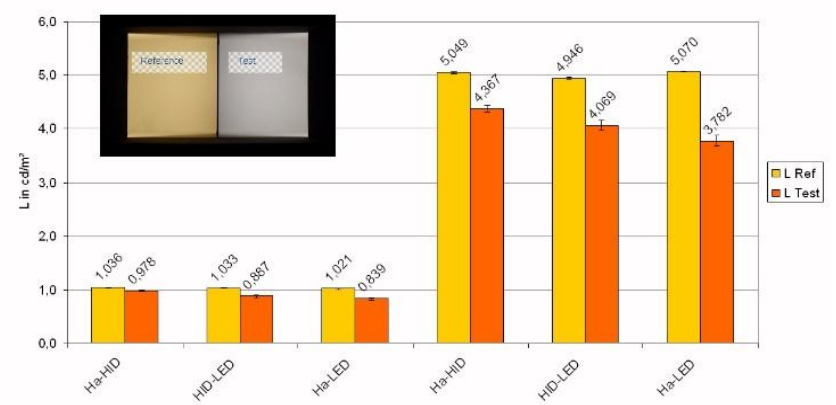

Figure 4: Luminance of the reference and test areas with matching

$$
P=\left[\frac{L_{r e f}-L_{t e s t}}{L_{r e f}}\right] \cdot 100 \%
$$

where: $P$ - perceptual decrease in test luminance, $L_{\text {ref }}$ luminance of the reference screen at equal brightness, $L_{\text {test }}{ }^{-}$ luminance of the test screen at equal brightness.

Table 2. Decrease in luminance at equal brightness of the test source Notes: * indicates the reference source, - no significant difference

\begin{tabular}{|c|c|c|c|c|c|c|}
\hline $\begin{array}{ll}P & \text { in } \\
\% & \end{array}$ & \multicolumn{3}{|c|}{$\begin{array}{l}\text { Main test } \text { (visual } \\
\text { field } 20^{\circ} \text { ) }\end{array}$} & \multicolumn{3}{|c|}{$\begin{array}{l}\text { Pilot study (visual fiel } \\
36^{\circ} \text { ) }\end{array}$} \\
\hline $\begin{array}{l}\mathrm{L}_{\text {ref }} \text { in } \\
\mathrm{cd} / \mathrm{m}^{2}\end{array}$ & $\begin{array}{l}\mathrm{Ha} \text { : } \\
\mathrm{HID}\end{array}$ & $\begin{array}{l}\text { HID*: } \\
\text { LED }\end{array}$ & $\begin{array}{l}\mathrm{Ha}^{*}: \\
\text { LED }\end{array}$ & $\begin{array}{l}\mathrm{Ha}^{*} \\
\mathrm{HID}\end{array}$ & $\begin{array}{l}\text { HID* } \\
\text { LED }\end{array}$ & $\begin{array}{l}\mathrm{Ha} \text { *: } \\
\text { LED }\end{array}$ \\
\hline 0.1 & 11 & - & - & 10 & 11 & - \\
\hline 1 & 5.6 & 14.1 & 17.8 & 14 & 28 & 23 \\
\hline 5 & 13.5 & 17.7 & 25.4 & 20 & 30 & 31 \\
\hline
\end{tabular}

\section{Analyses}

The results show two facts:

(1) The brightness of the road increases under mesopic conditions, if the light source contains higher parts of shorter wavelength. This leads to a better feeling of safety and to greater comfort for drivers.

(2) This effect increases with higher luminances for the investigated luminance range. This contradicts our theoretical expectations. Therefore further investigations during the last two years have confirmed the presented results, further investigations are necessary to close the gap of knowlegde.

\section{Areas of view during night-driving}

The human eye has different spectral sensitivity for the fovea centralis and the peripheral field under mesopic conditions, for this reason it is important to know the role of the peripheral field in night-driving. In an experiment carried out by Stahl [13] the direction of view of drivers at night was studied.

To explore the eye movement during night time driving an eye-tracking system was used. The system was mounted in a test car, see figure 5 . Six male test subjects took part, they were age between 22 and 34 years old and all drove more than $15,000 \mathrm{~km}$ per year. For the experiment they drove along a $15 \mathrm{~km}$ long real road.

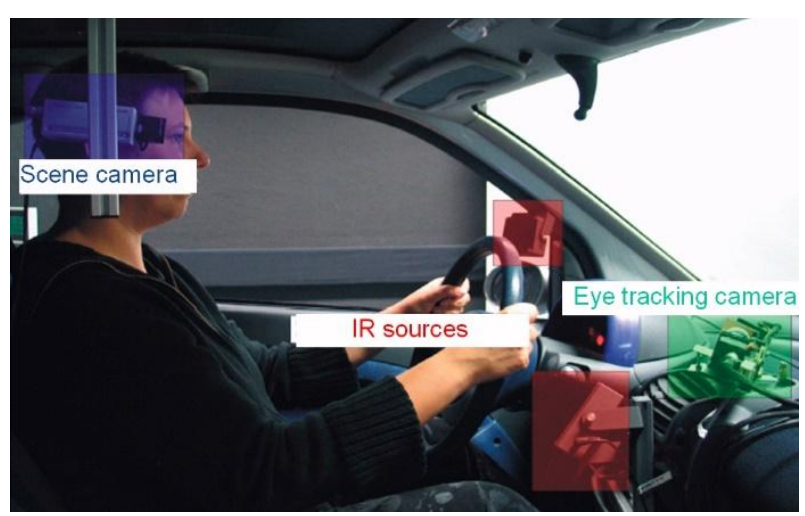

Figure 5. Eye-tracking system used for the recording of direction of view [13] 
The figures 6 and 7 show the accumulation point of view under night time conditions for a straight and a bending road. The direction of the centre of view for drivers on straight roads was generally close to directly ahead (within $\pm 4^{\circ}$ ), but much wider for bends in the road and complex situations.

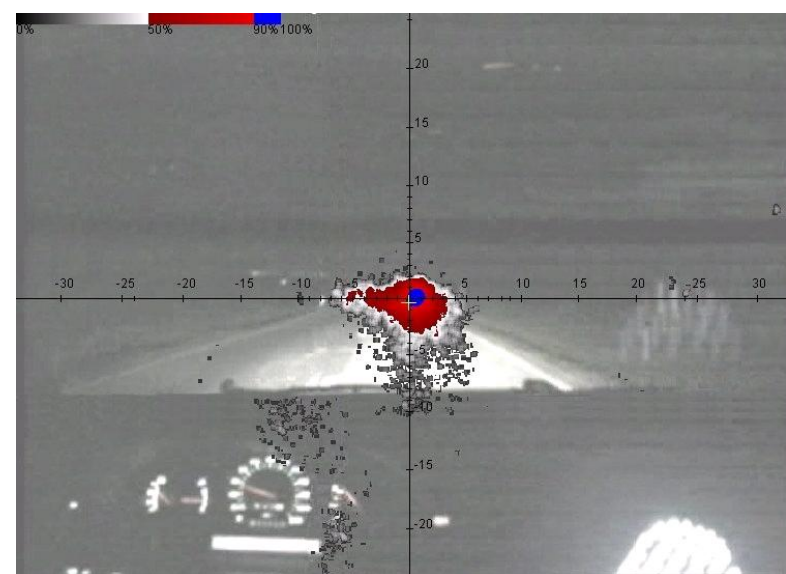

Figure 6: Accumulation point of view for a straight road [13]

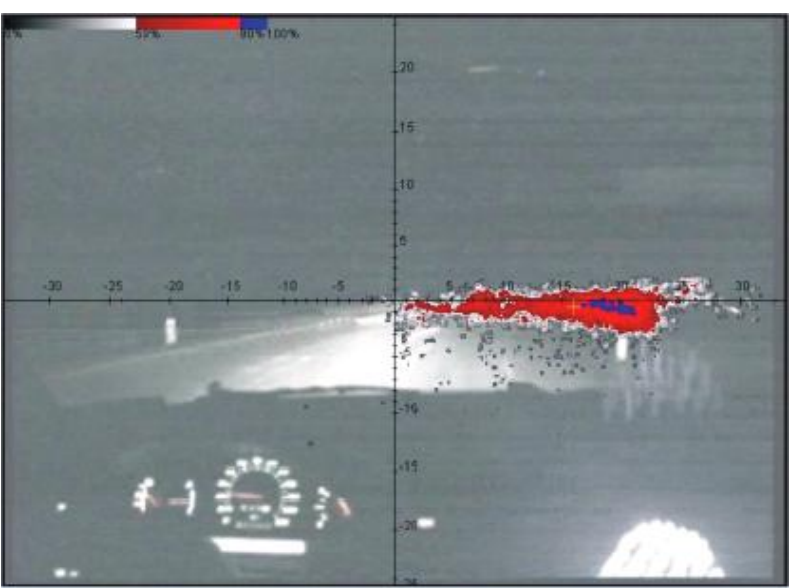

Figure 7, : Accumulation point of view for a bending road [13]

These results agree with a previous study by Diem [14].The area covered by the centre of view is dependent on the course of the road, the light distribution, the light source, the road conditions and the driver; however the differences between the test drivers were not large. The patterns of view direction can be used to surmise the strategy being used by the driver. However, the experiment could not reveal how much information drivers were obtaining from the peripheral field. Thus further tests will be needed to determine the role of the peripheral field in the night driving task.

Driving on roads with bends and in complex situations is completely different to straight roads. The centre of the point of view can move up to $30^{\circ}$ horizontally and $5^{\circ}$ vertically depending on the geometry of the road. By scanning the street the driver looks for obstacles. If an obstacle is detected by the peripheral field then the fovea is directed to it, at this point the driver can decide if avoiding action is necessary. The large movement of the eyes on bends and complex situations shows the importance of peripheral vision.

\section{Influence of the spectral distribution on the detection}

In the previous section the results of eye movement were discussed. Research has shown that the spectral sensitivity of the fovea does not change at mesopic light levels, whilst that of the peripheral field changes to become more sensitive to short wave radiation as lighting levels decrease. Most of the research already carried out has been in areas well away from the fovea, usually more than $10^{\circ}$. Thus there was a need to investigate the influence of spectral distribution in the zone closer to the fovea. Leibinger [15] has recently investigated the importance of spectral distribution on contrast sensitivity in the region between $2^{\circ}$ and $14^{\circ}$ from the fovea (published in English in [16]. For his experiment Leibinger used the facilities shown in figure 8.

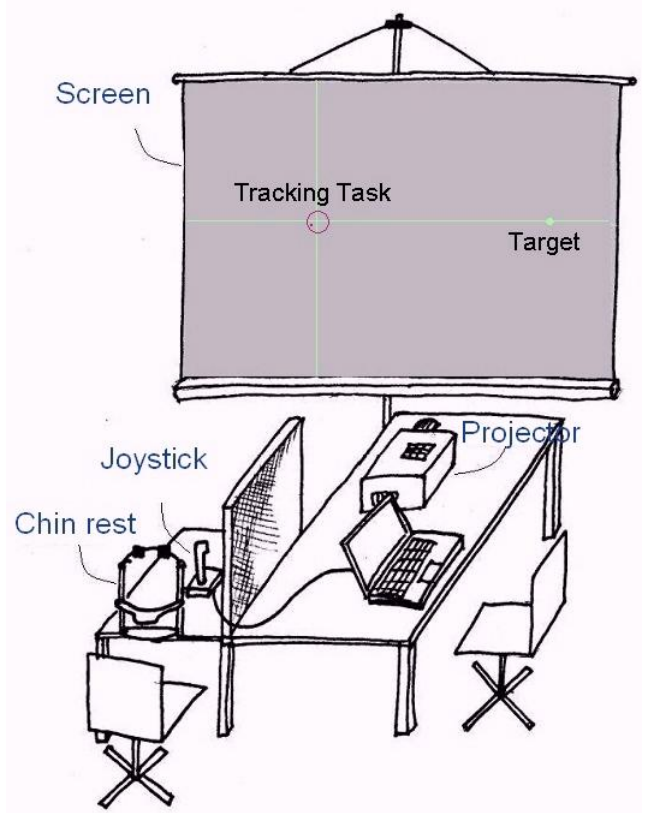

Figure 8. Testing facilities for the determination of the threshold contrast [15]

A total of 44 test subjects took part in the test; there were 33 men and 11 women with ages ranging from 16 to 32 with an average age of 24.7 years. During the test the subjects had to concentrate on the tracking task on the left of the screen, the test stimuli - a coloured disk - were presented on the right. The test stimuli were randomized and each being presented twice, they were $0.7^{\circ}$ in size and appeared for 0.5 seconds. Figure 9 shows the spectral distribution of the colour stimuli.

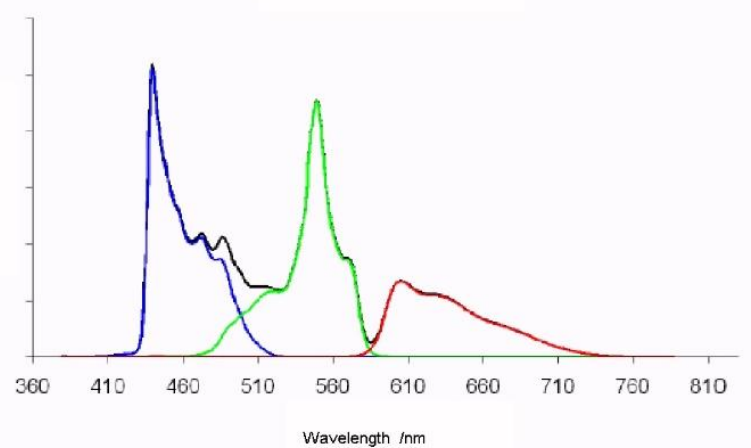

Figure 9. Spectral distribution of the colour stimuli's [15]

Figure 10 shows the variation of threshold contrast with eccentricity for the various colours of stimuli at a background luminance of $0.1 \mathrm{cdm} 2$. Figure 11 shows the contrast sensitivity for the various colours at an eccentricity of $10^{\circ}$ for various background luminances. 


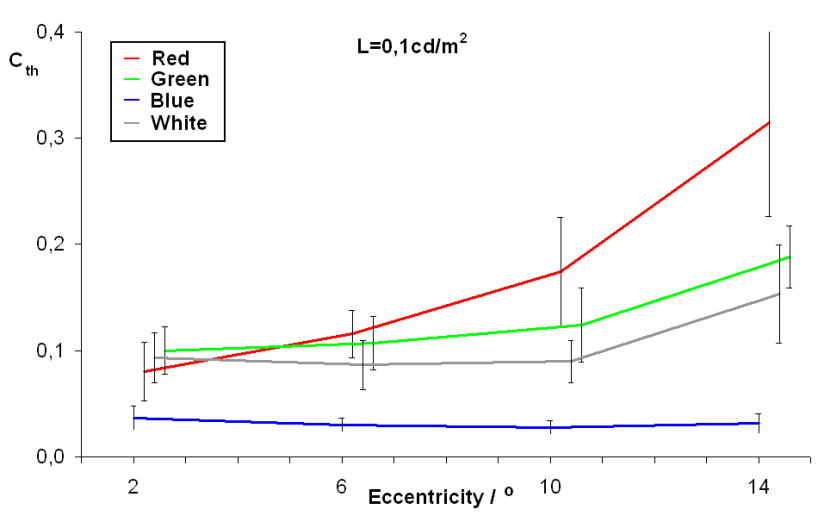

Figure 10. Threshold contrast as function of the background luminance for the three coloured stimuli [15]

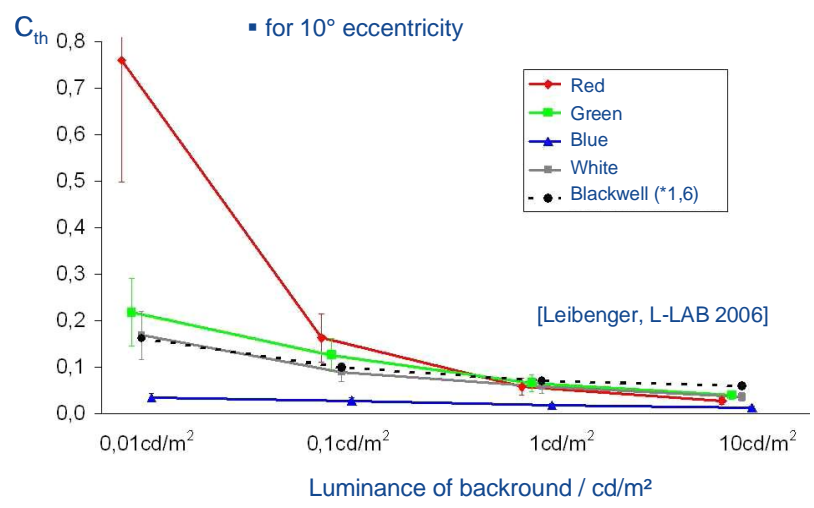

Figure 11. Threshold contrast as function of peripheral angle for the three coloured stimuli [15]

Table 3 shows the results of the variance analysis. It reveals that the background luminance has the biggest influence followed by the colour and the eccentricity.

Table 3. Results of the variance analysis for the threshold contrast [15]

\begin{tabular}{|l|l|l|}
\hline Influencing factor & $\mathrm{F}$ & Significance \\
\hline $\begin{array}{l}\text { Background } \\
\text { luminance Lu }\end{array}$ & 1015.86 & 0.000 \\
\hline $\begin{array}{l}\text { Colour of the } \\
\text { stimulus }\end{array}$ & 509.06 & 0.000 \\
\hline Colour $*$ Lu & 308.55 & 0.000 \\
\hline Eccentricity & 148.35 & 0.000 \\
\hline Colour $* \varphi$ & 75.41 & 0.000 \\
\hline & & \\
\hline$*$ Lu & 49.03 & 0.000 \\
\hline & & 0.000 \\
\hline
\end{tabular}

\begin{tabular}{|l|l|l|}
\hline Influencing factor & $\mathrm{F}$ & Significance \\
\hline Visual aids & 6.891 & 0.009 \\
\hline $\begin{array}{l}\text { Experience with } \\
\text { games }\end{array}$ & 2.835 & 0.059 \\
\hline Sex & 1.344 & 0.247 \\
\hline Frequency & 0.586 & 0.444 \\
\hline Age & 0.09 & 0.764 \\
\hline
\end{tabular}

The comparison between the threshold contrast of the white stimuli and the Blackwell [17] data demonstrates the necessity of a additional stress factor through the tracking task. Lachenmeyer [18] determined that a stress factor of 1.6 should be applied if a tracking task is used. The factor should be independent of the location on the retina. Figure 11 illustrates that the data of Blackwell and the presented data are comparable. Furthermore the results are also comparable with the results of Orreveteläinen [19].

This shows that a if a light source has a high blue content then the threshold contrast at eccentricities of $10^{\circ}$ or more is significantly lower than with sources with a lower blue content (higher red content). Thus light sources with a high blue content support peripheral vision. The area of the vision close to the fovea (within $5^{\circ}$ ) has a sensitivity function that substantially follows the $V(\lambda)$ function and so photopic values may be used to characterise visual performance.

The previous sections of this paper lead to the conclusion that for straight roads the photopic measure of illuminace is what determines the ability to perform the driving task. However, on bends and in complex situations a higher blue content to the light improves performance.

\section{Spectral and spatial distribution - which is more important?}

The variance analysis given in table 3 shows that luminance is the most important predictor for threshold contrast. However, in the tests carried out a large range of luminance values was used. Such a wide range of luminance values are not in practice achieved with real luminaries or headlamps. This topic has been investigated by Slabina [20], the methods used and the results are given below.

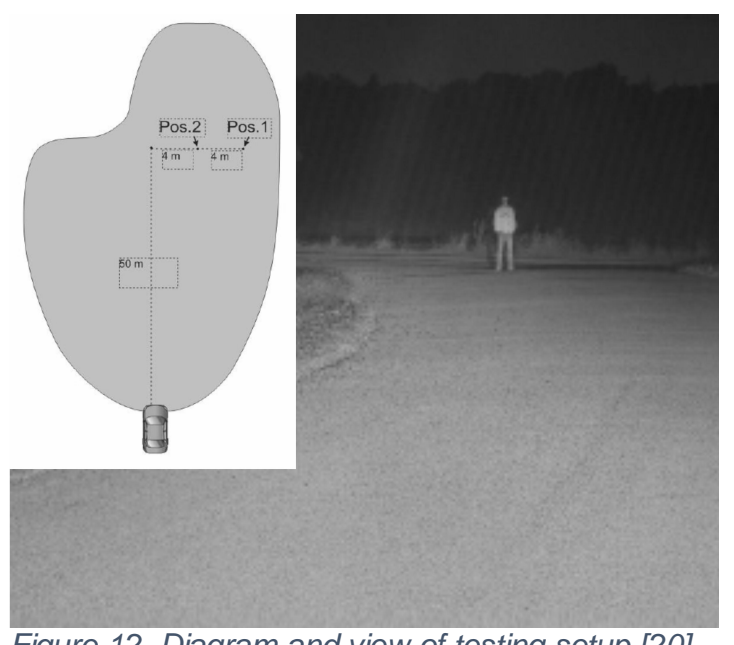

Figure 12. Diagram and view of testing setup [20]

Three different sorts of headlight were used (Halogen, HID and LED). They were mounted on a car and used to illuminate a person $50 \mathrm{~m}$ away on a closed country road. Figure 12 shows the scene as observed from the car. The person was dressed alternately in light and dark clothes. 
Figure 13 shows the luminance pattern for the person in light clothing.
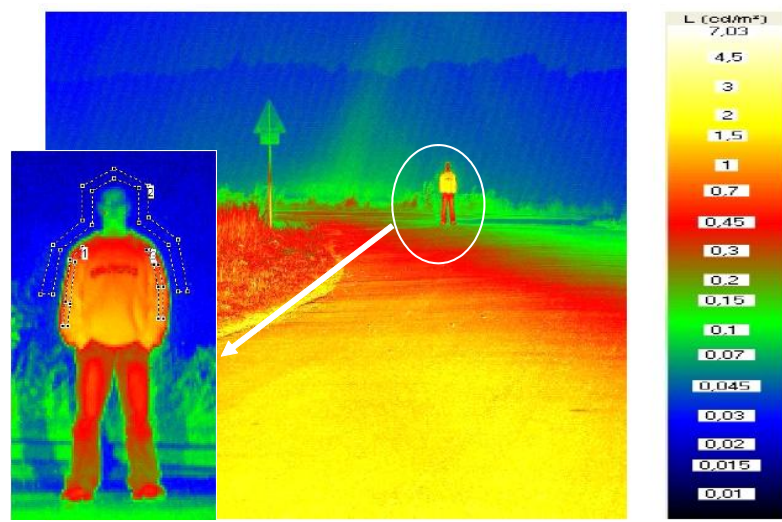

Figure 13. Luminance distribution of the street with person with light coloured clothes [Sla06]

The luminance distribution was measured for both clothing variations and the three different types of headlight. In addition, the scotopic luminance $\mathrm{L} 10^{\circ}$ and the chromaticity coordinates $x$ and $z$ were recorded.

Figures $14 \& 15$ show the calculated contrast of the person against the background of the different luminance pictures. The mesopic luminances were calculated using the model from Kokoschka [21], [22].

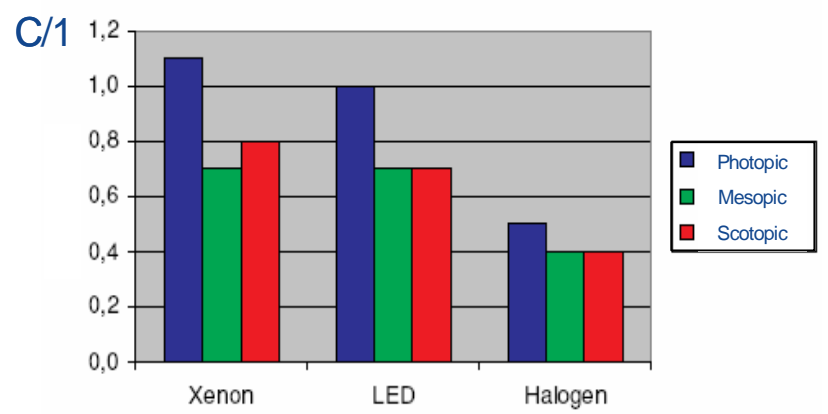

Figure 14. Calculated photopic, mesopic and scotopic contrast of the dark person $50 \mathrm{~m}$ ahead a car and $4 \mathrm{~m}$ right [20]

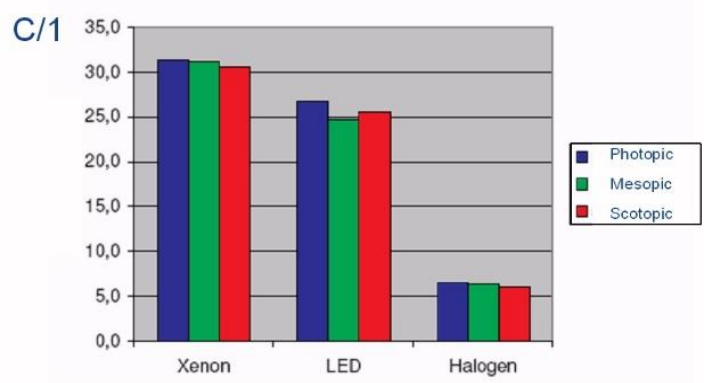

Figure 15. Calculated photopic, mesopic and scotopic contrast for the person with light clothes $50 \mathrm{~m}$ ahead a car and $4 \mathrm{~m}$ right [20]

The contrast for the person in light coloured clothes was always significantly higher than that for the dark clothes. The greatest contrast was produced by the Xe-system, followed by the LED-system and then the halogen system. The above results show that the spectrum of light used becomes more important as the luminance decreases. However, they also show that the spatial distribution of light is more significant than the spectrum of the light source. This implies that the optical design of headlights and luminaries is more important than the spectral output of the light source used in them.

\section{Conclusion}

This paper has illustrated that the purpose of pedestrian lighting and car lighting are not identical. The lighting requirements for safe movement, orientation and facial recognition are all different. There have been a number of investigations into the benefits of white light for pedestrians and they have shown that:

- White light is more pleasant for pedestrians,

- Colour recognition is better under white light in comparison to yellow light,

- Pedestrians are more visible under white light

- Recognition of faces by pedestrians is better.

The research reviewed in this shows that:

- The brightness of the road increases under mesopic conditions, if the light source contains more of short wavelength radiation.

- This can lead to a better feeling of safety and to more comfortable driving.

- Fast movement of eyes shows the peripheral field is very important for bends and complex traffic situations.

- The effect on straight roads is small, as demonstrated by the results of the eye tracking and threshold contrast experiments.

- The light distribution can be more important than spectrum.

This and other studies have shown that white light should be used for:

- Residential areas,

- Pedestrian zone,

- Areas with a high crime rate,

- All complex traffic points (crossways, pedestrian crossing) and

- For the illumination of bends.

The use of white light in the above situations can provide the necessary lighting conditions at lower levels of luminance and thus it is possible to provide less light and hence save energy. However, to derive the lighting level needed for a particular situation it is necessary to know what the equivalent mesopic luminance is. Currently there is no method for designing or measuring the output of lighting systems in terms of mesopic luminance. An investigation into the use of adaptive luminance imaging systems is being carried out at L-Lab with an objective of developing a method of assessing mesopic luminance in various situations.

\section{REFERENCES}

[1] BS 5489-1: 2003 Code of Practice for the Design of Road Lighting. British Standards, London

[2] Akashi, Y.; Rea, M.S.: Peripheral detection while Driving under a mesopic light level. Journal of the Illumination Engineering Society, 31 (1), p. 85-94, 2002

[3] Bullough and M.S. Rea, Visual Performance under mesopic conditions: Con-sequences for roadway lighting, Transportation Research Record (1862) pp 89-94; 2004

[4] Fotios, S.: Light source spectrum, brightness perception and visual performance in pedestrian environments: a review. Lighting Res. Technol. 37,4 (2005) pp. $271-294$

[5] Scott, A.: White Light - The UK Balance Sheet, The Lighting Journal, S. 18-20, Januar/Februar 2005

[6] Knight, C.; van Kemenade, J.: Wahrnehmung und Wertschätzung öffentliche Beleuchtung durch Endkunden. Licht 2006 Bern, Tagungsband 
[7] Fotios, S.; Cheal, C.: Lighting for subsidiary streets: investigation of lamps of different SPD. Part 1-Visual Performance

[8] Fotios, SA and Cheal, C. (2007) Evidence for response contraction bias in side-byside matching tasks; In: Lighting Research Technology 39,2 pp. $159-169$

[9a] Eloholma, M., Ketomäki J., Orreveteläinen, P. and Halonen, L.. Pedestrian visibility in road lighting conditions. HUT Lighting Laboratoy, Report 30, 2004.

[9b] Raynham, P.; Saksvikronning, T.: White Light and Facial Recognition, The Lighting Journal, S. 29-33, Januar/Februar 2003

[10] Bullough, J.: Is White Light a White Knight? Research Matters pp 24-26 (2006)

[11] Lewin, I.: Lumen Effectiveness Multipliers for Outdoor Lighting Designs, IES Paper No. 50; 2001

[12] Gottschalk, M.: Das Hellempfinden im mesopischen Bereich in Abhängigkeit vom Farbort. Diplomarbeit L-LAB/FH Köln, 2007

[13] Stahl, F.: Kongruenz des Blickverlaufs bei virtuellen und realen Autofahrten -Validierung eines Nachtfahrsimulators; Diplomarbeit L$\mathrm{LAB} / \mathrm{TU}$ IImenau 2004

[14] Diem, Carsten (2005): Blickverhalten von Kraftfahrern im dynamischen Strassenverkehr. München: Utz (Darmstädter Lichttechnik)

[15] Leibinger, M.: Kontrastempfindlichkeit unter mesopischen Adaptationsbedingungen. Diplomarbeit L-LAB 2006

[16] Raphael, S., Leibinger, M.: Models of mesopic photometry applied to the contrast threshold of peripheral and foveal objects. CIE conference 2007 Beijing, Proceedings D 1-38

[17] Blackwell, H. R.Contrast thresholds of the human eye, Journal of the Optical Society of America, Vol. 36, No. 11

[18] B. Lachenmayr. Die Bedeutung des peripheren Sehens fäur den Kraftfahrer. Fortschritte der Ophthalmologie, 83:357-360, 1986.

[19] Orrevetelainen, P.: Models of spectral luminous efficiency in peripheral vision at mesopic and low photopic luminance levels. Dissertation of Helsinki University of Technology, Lighting Laboratory, August 2005

[20] Slabina, R.: Darstellung von Leuchtdichtebildern auf der Retina - Implementierung praxisrelevanter Einflussfaktoren. Diplomarbeit LLAB/FH Jena Augenoptik. 2006

[21] Kokoschka, S.: Photometrie niedriger Leuchtdichten durch eine äquivalente Leuchtdichte des $10^{\circ}$ Feldes. Licht-Forschung Vol 2, Nr. 1, S.1-13, 1980

[22] CIE-Publication No. 19/2.1, 19/2.2: An analytical model for describing the influence of lighting Parameters upon visual performance, 1972, 1981

\section{Author:}

Prof. Dr.-Ing. Stephan Voelker, TU Berlin, Fachgebiet Lichttechnik (E6), Einsteinufer 19, Germany,

e-mail: Stephan.voelker@tu-berlin.de 